Revista Iberoamericana, Vol. LXXIII, Núm. 221, Octubre-Diciembre 2007, 735-741

\title{
TECNO-ESCRITURA: LITERATURA Y TECNOLOGÍA EN AMÉRICA LATINA
}

\author{
POR
}

J. ANDREw Brown

Washington University in St. Louis

En 1994, Beatriz Sarlo describió la experiencia de visitar un club de video-games en Buenos Aires:

\begin{abstract}
Las paredes del salón están pintadas de colores ácidos, verde manzana, amarillo, violeta; contra estos planos de color rebotan las luces que cuelgan del techo y también reverberan algunos grafismos en neón, rayos, estrellas, espirales. Como sea, nadie mira ni las paredes, ni el techo; nadie tiene tiempo para desplazar la vista. Saben que hay poco para ver. El ruido de la música, una percusión que se repite sin variaciones detrás de una melodía brevísima, bien simple, que también se repite sin variaciones, está mezclado con otra serie de sonidos: silbidos, golpes metálicos, golpes asordinados, breves ondas eléctricas, matracas, acordes de sintetizador, tiros, voces irreconocibles, boing, tong, clash, la banda sonora de la historieta. (Escenas 44-5)
\end{abstract}

Sarlo adopta un tono de antropóloga observando y reportando una cultura extranjera, una donde los "nativos" parecen absorbidos por un ambiente hipertecnologizado. La descripción del local evoca los mundos virtuales de la tecnología con sus luces y colores artificiales y, simultáneamente, el mundo de la cultura pop donde el lugar físico se convierte en historieta completa con una banda sonora que evoca la serie televisiva Batman. Después Sarlo llama al club un "signo de una época” identificando al lugar que se ha presentado como un espacio de ciencia ficción como el anuncio de lo que vendría en el nuevo mundo posmoderno (55). Ahora, unos doce años después, vemos que Sarlo anticipaba de manera casi profética los cibercafés que aparecen en cada cuadra de las ciudades de América latina y los cambios enormes que colocarían a ese mundo tecnológico en un lugar prominente en el estudio de la cultura latinoamericana.

La expansión rápida y global de nuevas tecnologías y el desarrollo de los medios políticos, económicos y, sí, tecnológicos que facilitan tal expansión ejercen un impacto cultural difícil de sobreestimar. García Canclini, en la introducción a la reedición (2001) de su libro Culturas híbridas, identifica la tecnología como uno de los motores fundamentales del proceso de la hibridización que percibe en América latina,

Todas las tendencias de abdicación de lo público en lo privado, de lo nacional en lo transnacional, que registrábamos hace diez años se han acentuado. Dos procesos nuevos, 
incipientes entonces, colaboran en esta reorientación. Uno es la digitalización y mediatización de los procesos culturales en la producción, la circulación y el consumo, que transfiere la iniciativa y el control económico y cultural a empresas transnacionales. Otro abarca el crecimiento de los mercados informales. [...] La hibridación en cierto modo se ha vuelto más fácil y se ha multiplicado cuando no depende de los tiempos largos, de la paciencia artesanal o erudita, sino de la habilidad para generar hipertextos y rápidas ediciones audiovisuales o electrónicas. (xvii-xviii)

Jesús Martín-Barbero también une expansión tecnológica y globalismo:

Confundida por muchos con el viejo y persistente imperialismo, asimilada a la transnacionalización, o mejor a la expansión acelerada de las lógicas y las empresas transnacionales, identificada con la revolución tecnológica y con el impulso secreto de la posmodernidad, la globalización diluye sus contornos hasta hacerse inasible en medio de una infinita proliferación de artículos y libros a cual más decepcionante. (Al sur 103)

Los dos pensadores exploran el vínculo entre proyectos neoliberales y la expansión global de tecnologías de comunicación, notando en particular que esas tecnologías llevan necesariamente en sí los intereses de las transnacionales, con todas las riesgosas implicaciones que esta unión promete.

La obra de estos intelectuales es contemporánea a una serie de articulaciones teóricas de nuevos paradigmas tecnológicos. Cabe destacar la obra de Donna Haraway, crítica feminista y científica que en "A Cyborg Manifesto" ha provocado reacciones y reevaluaciones de la cultura tecnofílica. Vemos la influencia de su mito cyborguiano en la obra de Michael Hardt y Antonio Negri que toman la desconstrucción que hace Haraway de los sistemas patriarcales del capitalismo y militarismo como elemento fundamental del nuevo “imperio" que ellos proponen. La vemos también en algunas lecturas de la novela La ciudad ausente (1993) de Ricardo Piglia donde una mujer cibernética narra historias traumáticas de la Argentina. La llegada de la identidad poshumana ha capturado el interés de varios críticos y artistas latinoamericanos que, aunque no siempre siguen las interpretaciones propuestas por Haraway o N. Katherine Hayles, ofrecen nuevas e innovadoras maneras de entender las relaciones que ahora existen entre cuerpos orgánicos y la tecnología que los rodea.

En el campo de los estudios específicamente literarios, hemos visto una serie de publicaciones que intentan elucidar un tratamiento largo y extensivo de la tecnología en la literatura latinoamericana. Jane Robinett, en su libro This Rough Magic (1994), explora las dinámicas del "otro” y lo extranjero en la representación de la tecnología en obras tan canónicas como Cien años de soledad. En el libro más reciente Science, Technology, and Latin American Narrative in the Twentieth Century and Beyond (2000), Jerry Hoeg explora los nuevos y variables acercamientos a una tecnología que es a la vez extranjera y nativa. Postula a la tecnología y los medios masivos como un nuevo archivo latinoamericano (evolución de los propuestos por González Echeverría en Myth and Archive). Concluye: 
As we look back on the various takes on science and technology produced by Latin American narrative, we see that what many of these do is perpetuate the discourse of Modernity. They may say that they are for, against, or simply neutral with regard to technology, but generally the underlying message is mediated by the metaphysics of Modernity... (122)

Este vínculo entre la tecnología y el discurso de la modernidad es el vínculo que vemos establecerse no sólo en los estudios literarios que examinan el tratamiento temático de la tecnología, sino en los estudios culturales que intentan entender el impacto de nuevas tecnologías en la formulación de la cultura latinoamericana. El argumento que corre de Sarlo a Hoeg y que pasa por todos los otros críticos mencionados aquí, es que la tecnología ofrece una perspectiva única e importante de cómo la modernidad, y la posmodernidad, se está articulando y rearticulando en América latina.

Como expresión artística y cultural, además de proyecto económico, la literatura se ha hecho partícipe de los “procesos nuevos” que identifica García Canclini. Es importante recordar, sin embargo, que esa nueva realidad posmoderna donde el arte se tecnologiza como resultado de fuerzas globalizadoras y neoliberales es sólo una de las caras de la dinámica que opera al intersectarse el proceso creativo y el ambiente tecnológico en que ese proceso ocurre. Si expandimos nuestro enfoque para incluir una consideración del trasfondo tecnológico de la literatura (y el trasfondo literario de la tecnología), empezamos a percibir una relación simbiótica que es a la vez rica y aterradora. Tomemos, por ejemplo, a Martín-Barbero otra vez, prestando atención no sólo a su análisis cultural sino también a la escritura que emplea en este análisis. Cuando habla de las nuevas cartografías de ciudades latinoamericanas, ciudades que él ha llamado "virtuales” (Al sur 125), describe cartografías movedizas que incluyen el:

mareamiento de circuitos y trayectos que de-velan en las cibernéticas metrópolis actuales de ciudades invisibles: místicas, esotéricas, vivenciales. Y desde las cartografías catastrales construidas desde arriba, y a las que "nada escapa" como el panóptico aquel que estudiara Foucault, sólo que ahora su centro es móvil -la cámara colocada en el helicóptero. (Oficio 13)

Aquí el tema tecnológico que Martín-Barbero ha estudiado de manera detenida y llamativa configura su propio discurso. La metáfora ya cansada de la "Information Superhighway” que recibe tanta atención en la prensa norteamericana aparece en el texto de Martín-Barbero en imágenes más sofisticadas donde los circuitos silíceos de un chip de computadora representan las nuevas calles y avenidas de las ciudades virtuales que describe. La conversión metafórica de la nueva ciudad latinoamericana en computadora establece su interpretación del helicóptero de las noticias televisivas como el nuevo panopticón foucaultiano mientras representa simultáneamente esa nueva realidad tecnológica en los únicos términos apropiados. Lo que vemos en el trabajo de MartínBarbero y de otros teóricos es una situación en que la "revolución tecnológica” determina la misma semiótica del discurso usado para describirla. 
El objetivo de este volumen es, entonces, considerar las múltiples dinámicas en que literatura y tecnología se encuentran como partícipes de realidades culturales en un flujo constante. Se ha intentado incluir análisis de varios momentos de la historia de una relación complicada y duradera, que abarca de manera importante la historia de la literatura latinoamericana del siglo xx y que ahora al comienzo del siglo xxi se ha vuelto aun más vigente. Consideraremos esa relación desde el impacto de la fotografía y la radio en la narrativa y la poesía del comienzo del siglo hasta el análisis de poesía en Internet y la articulación de cuerpos poshumanos en la narrativa de las últimas décadas.

Cómo aprendimos de Sarlo en La imaginación técnica (1992) -un estudio anterior a Escenas de la vida posmoderna donde explora fructíferamente las interacciones entre nuevas tecnologías y el trabajo literario de Horacio Quiroga y Roberto Arlt- la dinámica tan fértil que existe entre tecnología y producción cultural en Latinoamérica no comienza con la explosión reciente de tecnología informática. En la primera sección incluimos tres artículos que se combinan para proveer una exploración panorámica de la función de la fotografía en la escritura latinoamericana. En "Llévese la cámara a la tumba: deseo fotográfico en cuatro cuentos de Lugones”, Valeria de los Ríos toma como enfoque la llegada de la tecnología fotográfica a Latinoamérica al analizar la obra del escritor argentino. Muestra cómo esa serie de cuentos responde a los temores y posibilidades de la nueva tecnología mientras establece el contexto histórico y científico que informa las decisiones artísticas de Lugones y otros escritores de la época.

En "La imagen fotográfica, entre el aura y el cuestionamiento de la identidad: una lectura de ‘La paraguaya’ y La invención de Morel”, Edmundo Paz Soldán, un escritor que ha explorado a fondo las nuevas tecnologías de la imagen en novelas como Sueños digitales (2000) y El delirio de Turing (2003), adopta el papel de crítico para examinar la fotografía como punto de unión entre la conocidísima novela de Adolfo Bioy Casares y el cuento menos conocido de Augusto Céspedes. Encuentra en los dos textos un uso de la fotografía para reimaginar la naturaleza de la identidad y de la escritura que se usa para explorar esa identidad. Las narrativas de los dos escritores no sólo dan evidencia de cambios profundos en lo que Paz Soldán llama la “ecología mediática” de sus sociedades, sino que ejemplifican el proceso por el cual el arte escrito evoluciona frente a nuevos desarrollos en la tecnología de la representación.

La sección termina con "Fotografía y escritura en Autobiografía precoz de Salvador Elizondo" donde Sergio R. Franco explora la manera en que el escritor mexicano responde a realidades fotográficas en la reedición en el año 2000 de su Autobiografía publicada originalmente en 1966. Franco examina detenidamente la interrelación dinámica entre lenguaje escrito y fotográfico en el texto de Elizondo, encontrando que la tecnología fotográfica contribuye a la producción paradójica de un sujeto autobiográfico que disfruta del "aura” benjaminiana del artista y, simultánea y contradictoriamente, del alcance masivo de la reproducción.

En la próxima sección, sobre poshumanidades latinoamericanas, se exploran las expresiones diversas de las identidades que surgen de las relaciones íntimas que los cuerpos orgánicos emprenden con la tecnología que los rodea y constituye. En "Do implantado ao ciborgue: o corpo social na ficção científica brasileira”, Elizabeth Ginway 
se enfoca en la ciencia ficción brasileña reciente para entender cómo los cuerpos cibernéticos revelan dinámicas culturales importantes en un Brasil tecnologizado. Encuentra que la articulación del cuerpo literalmente cyborg en ese género propone un cuerpo político latinoamericano que consiste de valores e ideologías marcadamente distintos de las teorías de la identidad poshumana que se han propuesto en el llamado "primer mundo".

En "Identidad poshumana en Lóbulo de Eugenia Prado", tomo la novela de una escritora chilena poco conocida para explorar cómo una novela que marcadamente no es de ciencia ficción depende de imágenes y expresiones de la identidad poshumana para estetizar nuevas mentalidades. Incorporo críticamente las teorías poshumanas y cyborguianas de Haraway y Hayles y las teorías de Gilles Deleuze y Félix Guattari para analizar la articulación de cuerpos y subjetividades cuya naturaleza orgánica es alterada de manera fundamental por la tecnología ubicua que los rodea. En Lóbulo, específicamente, encontramos propuestas de una visión de la identidad poshumana que van más allá de las teorías cyborguianas basadas en la literatura norteamericana y europea o en una conceptualización de una cultura globalizada propuesta por teóricos de la academia norteamericana.

Emily Hind da fin a la sección con "Un ¡ojo! tecnológico: novelas raras contra miradas maquinales del cine mexicano”, donde analiza la interacción de la narrativa y el cine mexicanos recientes al nivel de la teoría queer y la mirada tecnológica. Usando las películas Nicotina, En el país de no pasa nada y Fantasías junto a las novelas Cielos de la tierra de Carmen Boullosa y Lejos del paraíso de Sandro Cohen, Hind investiga la articulación de una mirada "rara” y su función en una serie de narrativas que meditan sobre los temas de tecnología, sexualidad y nacionalidad en México y que plantean una dinámica mucho más compleja que una sólo de rechazo o aceptación de las nuevas tecnologías.

La última sección incluye discusiones de varios géneros y tecnologías a lo largo del siglo xx. En "Poesía sin hilos: radio y vanguardia”, Rubén Gallo discute el impacto fundamental de la radio en la poesía mexicana estridentista del comienzo del siglo xx. Gallo arguye que la nueva tecnología de la radio influyó de manera fundamental en la creación poética de la época, desde el nivel temático a, de manera más importante, los niveles estructurales y acústicos. En el caso de los estridentistas, Gallo nota, encontramos a artistas que no sólo se inspiraron en la nueva tecnología sino que participaron en la radiodifusión de su obra, y formaron parte de la creación de una nueva poesía vanguardista y un nuevo género artístico basado en la radio como medio de transmisión literaria.

Con “El foro de poesía en la Red: autopoiesis virtual ante el fenómeno ‘lisaymona’” de Alejandro Palma Castro, encontramos la poesía al final del siglo xx en otro medio tecnológico. La realidad nueva que describe García Canclini con el impacto de la digitalización fácil y los nuevos medios de distribución encuentra su expresión máxima en el fenómeno de poesía-Internet donde la accesibilidad y la inmediatez de la publicación electrónica combinadas con la creación de comunidades virtuales de lectores y escritores han ocasionado un nuevo género de expresión poética. Palma Castro investiga lo que se ha llamado "el fenómeno lisaymona" en el sitio de Internet poesia.com, analizando los textos poéticos de la identidad virtual lisaymona y, a la vez, teorizando el género de la poesía-Internet, explorando las varias problemáticas del nuevo medio para la expresión y el estudio de esa poesía. 
Claudio Canaparo elige el género de la historieta para llevar a cabo un estudio de la manera en que se emplean la ciencia y la tecnología como medios de exploración social en "Mobilis in mobili: ciencia y tecnología en El Eternauta". Canaparo examina detenidamente el manejo de la tecnología y la ciencia como términos teóricos y culturales en la historieta además de la manera en que Oesterheld manipuló los géneros de la historieta, la ciencia ficción y la ficción tecnológica y la cultura popular para crear un texto de un compromiso social notable.

Jerry Hoeg extiende la investigación de su libro a una consideración del impacto del tratamiento narrativo latinoamericano de la tecnología en la narrativa española contemporánea. En "La ciudad de los prodigios de Eduardo Mendoza frente a una visión latinoamericana de ciencia, cultura y tecnología”, Hoeg traza las articulaciones de la tecnología en novelas de García Márquez y Laura Esquivel, entre otros escritores latinoamericanos, para elucidar la dinámica desde la que funciona en la novela del escritor español. Al hacer eso, Hoeg revela un elemento importante de las relaciones transatlánticas de la narrativa hispana contemporánea.

En “Ni apocalípticos ni integrados: medios audiovisuales en tres narradores del Sur de América”, Jesús Montoya Juárez examina el papel tecnológico de los medios masivos en una constelación de tres novelas recientes de Bolivia, Uruguay y Argentina. Empezando con Sueños digitales de Edmundo Paz Soldán y después pasando a Caras extrañas (2001) de Rafael Courtoisie y La mendiga (1998) de César Aira, Montoya traza las maneras en que la narrativa configura y es configurada por las nuevas tecnologías audiovisuales. Encuentra que los tres novelistas construyen independientemente narrativas donde no sólo los personajes navegan nuevas realidades hipertecnologizadas sino que el discurso mismo de la novela simula los medios representativos posibilitados por la tecnología.

Termina el volumen con una entrevista al escritor uruguayo Rafael Courtoisie donde contextualiza una obra que ha explorado varios niveles de los discursos científicos, tecnológicos y massmediáticos en textos como Estado sólido (1996), Tajos (2000) y Caras extrañas, entre muchos otros. Courtoisie provee otra perspectiva a la discusión, una que toma en cuenta las realidades examinadas por Sarlo, García Canclini y Martín-Barbero mientras comenta sobre los esfuerzos de un artista para producir literatura dentro de un ambiente profundamente tecnologizado.

En todos los artículos y la entrevista reunidos en este volumen se aprecian las múltiples maneras en que la tecnología y la literatura se escriben la una a la otra. En eso, el chip silíceo que proveyó la imagen tan apropiada para la cartografía de Martín-Barbero también sugiere una interpretación del flujo de fuerzas culturales, realidades socioeconómicas y producción creativa que convergen en una tecno-literatura. Si bien ese chip facilita la escritura, producción y distribución de la expresión literaria por su presencia en las computadoras y máquinas que rigen el proceso entero de hacer llegar el texto literario de autor a lector, también lleva grabados en sí los diseños, circuitos e instrucciones que lo hacen otro texto más. La palabra tecno-escritura del título del volumen intenta llegar a esa realidad simbiótica y dinámica en que la literatura y la tecnología se combinan en productor, producción y producto de la cultura en que vivimos. 
BiBLIOGRAFÍA

García Canclini, Néstor. Culturas híbridas: estrategias para entrar y salir de la modernidad [1989; 2001]. México: Grijalbo, 2005.

Haraway, Donna J. Simians, Cyborgs, and Women: The Reinvention of Nature. Nueva York: Routledge, 1991.

Hardt, Michael y Antonio Negri. Empire. Cambridge: Harvard UP, 2000.

Hayles, N. Katherine. How We Became Posthuman: Virtual Bodies in Cybernetics, Literature, and Informatics. Chicago: U of Chicago P, 1999.

Hoeg, Jerry. Science, Technology, and Latin American Narrative in the Twentieth Century and Beyond. Bethlehem: Lehigh UP, 2000.

Martín-Barbero, Jesús. Oficio de cartógrafo. Travesías latinoamericanas de la comunicación en la cultura. México: FCE, 2002.

Al sur de la modernidad: comunicación, globalización y multiculturalidad. Pittsburgh: IILI, 2001.

Robinett, Jane. This Rough Magic: Technology in Latin American Fiction. Nueva York: Peter Lang, 1994.

Sarlo, Beatriz. Escenas de la vida posmoderna. Intelectuales, arte y videocultura en la Argentina. Buenos Aires: Ariel, 1994.

La imaginación técnica. Sueños modernos de la cultura argentina. Buenos Aires: Nueva Visión, 1992. 
